\title{
Validation and Optimization of Suspension Design for Testing Platform Vehicle
}

\author{
Luhang Li, ${ }^{1}$ Lin Xu $\mathbb{D},{ }^{1}$ Hao Cui, ${ }^{1}$ Mohamed A. A. Abdelkareem $\mathbb{D}^{2}{ }^{2}$ Zihao Liu, \\ and Jingyu Chen ${ }^{1}$ \\ ${ }^{1}$ Hubei Key Laboratory of Advanced Technology for Automotive Components, Wuhan University of Technology, \\ Wuhan 430070, China \\ ${ }^{2}$ Automotive and Tractors Engineering Department, Faculty of Engineering, Minia University, El-Minia 61915, Egypt \\ Correspondence should be addressed to Lin Xu; xulin508@whut.edu.cn
}

Received 8 June 2021; Accepted 24 August 2021; Published 3 September 2021

Academic Editor: Ricardo A. Ramirez-Mendoza

Copyright (c) 2021 Luhang Li et al. This is an open access article distributed under the Creative Commons Attribution License, which permits unrestricted use, distribution, and reproduction in any medium, provided the original work is properly cited.

With the application and popularization of the advanced driving assistance system (ADAS), the reliability and stability of ADAS have become its research focus. This article presents a car testing framework for ADAS reliability and stability. Its special suspension has been designed, verified, and optimized in real vehicles according to its working conditions. First, the structure and working principle of the testing platform vehicle are introduced. Then a simulation model is built in MATLAB/Simulink based on the dynamic equation to verify the working characteristics of the suspension. Experimental vehicle tests are conducted for simulation verification purposes. During the analysis, the root-mean-square (RMS) values of vehicle body displacement and dynamic tire deflection are considered evaluation indices. The nondominated sorting genetic algorithm (NSGA-II) is used to optimize the damping, stiffness, and installation position of the suspension system. The findings demonstrate that the specially designed suspension in this article can fulfill the test criteria. Compared with the optimized suspension performance, both the vehicle body displacement and dynamic tire deflection have decreased roughly by 17 and 40\%, respectively, which significantly improves the suspension performance and provides a reference for the future designs of testing platform vehicles.

\section{Introduction}

With the continuous improvement of consumers' understanding and demand for vehicle safety, the development and application of ADAS technology have become an important bargaining chip for the market competitiveness of auto companies [1]. It is of practical significance to allow more vehicles to be equipped with safety systems, which can reduce injuries and deaths more effectively. In addition to studying the new functions of ADAS, ensuring the reliability and stability of ADAS functions in the vehicle environment has become a difficulty in its development [2]. Problems can only be identified as early as possible through a complete ADAS test process. They can be investigated for the hidden functional defects, unreasonable points, and safety of the ADAS technology application to ensure functional integrity and reliability, thereby guaranteeing the product's central competitiveness, driver safety, and pedestrian safety on the market [3]. The way to verify the reliability and stability of the ADAS system is divided into software simulation and vehicle test [4]. Although software simulation can verify the performance of ADAS at a lower cost and in a shorter time, it still needs to be tested in real vehicles [5]. In verifying the vehicle's performance under test (VUT), it is necessary to restore the real driving environment to the greatest extent while minimizing the possibility of damage to the VUT and minimizing the risk to the driver of the vehicle VUT [6]. With the advancement of technology, field test has evolved from static test to dynamic and intelligent test [7]. The testing target vehicle, named ASSESSOR, that was developed by companies such as Daimler and Bosch has good collision tolerance and can withstand $200 \mathrm{impacts}$ at a speed of $50 \mathrm{~km} / \mathrm{h}$, but it can only be used for static test and cannot meet the requirements of 
the testing scenario [8]. In view of this, IDIADA's testing target vehicle [9] has been subject to corresponding improvements. The testing target vehicle is suspended on the boom fixed on the tractor, so it has dynamic performance and has the advantages of speed accuracy and easy control of the lateral offset. However, due to the addition of a tractor, the cost is increased. The Euro NCAP balloon car that was developed by Continental Corporation [10] cancels the tractor and adds a track under the testing target vehicle for dynamic test. Due to the use of the track method, the maneuverability is reduced. In order to improve the dynamic testing performance of the testing target vehicle, Dynamic Research, Inc. has developed an assembly target vehicle named Soft Car, which is carried by lowprofile robotic vehicle (LPRV) [11]. LPRV has power equipment, which significantly improves dynamic testing performance, but LPRV does not have a telescopic suspension device, and the handling stability is not good.

According to the results of several global coordination seminars organized by Euro NCAP, the National Highway Traffic Safety Administration (NHTSA) and the Insurance Institute of Highway Safety (IIHS), as well as the prestudy of Dynamic Research, Inc., NCAP has defined a three-dimensional target vehicle named global vehicle target (GVT). The GVT specification was formulated in May 2018 [12]. The Euro NCAP AEB C2C \& LSS Test Protocols pointed out that it is necessary to use GVT that meets the specifications for testing (Figure 1).

However, GVT is not powered and cannot conduct dynamic real-vehicle testing alone, so a low-chassis testing platform vehicle must be used to carry it. During the test, a low-chassis vehicle similar to the low-profile robotic vehicle is needed. The application scenario of the testing platform vehicle is shown in Figure 2. This method of using a low chassis to carry a testing target vehicle has become the mainstream of current research because of its higher maneuverability. Aiming at the driving method of this lowchassis testing platform vehicle, Zhang et al. used a timing belt method to drive the driving wheel and the driven wheel, thereby moving the testing platform vehicle [13]. To improve the reliability of the timing belt drive, Du et al. added a structure to adjust the distance between the driving wheel and the driven wheel on the basis of the timing belt for power transmission to further improve the system [14]. Given the shortcomings of LPRV without suspension, some scholars have studied its overload protection. For example, Huang et al. used the cylinder-driven suspension system to achieve the lifting of the wheels to reduce the damage to the wheels in the collision of the testing platform vehicle [15]. To protect the wheels, Li et al. chose the structure of universal joints and shock absorbers to achieve overload protection [16]. These methods can protect the wheels but introduce new structures and increase the complexity of the system.

In response to the existing problems, this paper designed a novel ultralow-chassis testing platform vehicle, which has good maneuverability and adopts a unique suspension system, which increases the overload protection of the system and can meet the testing scenarios of VUT better. The experimental part in the article also proved this point.

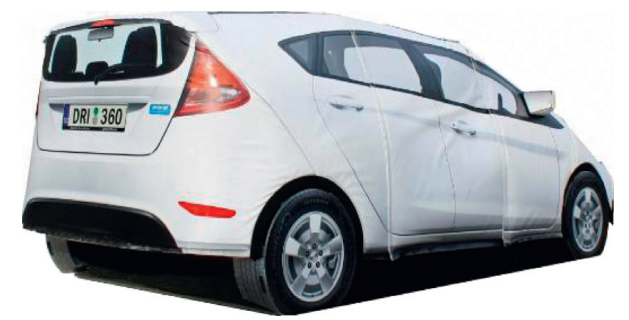

FIgUre 1: Specification of GVT.

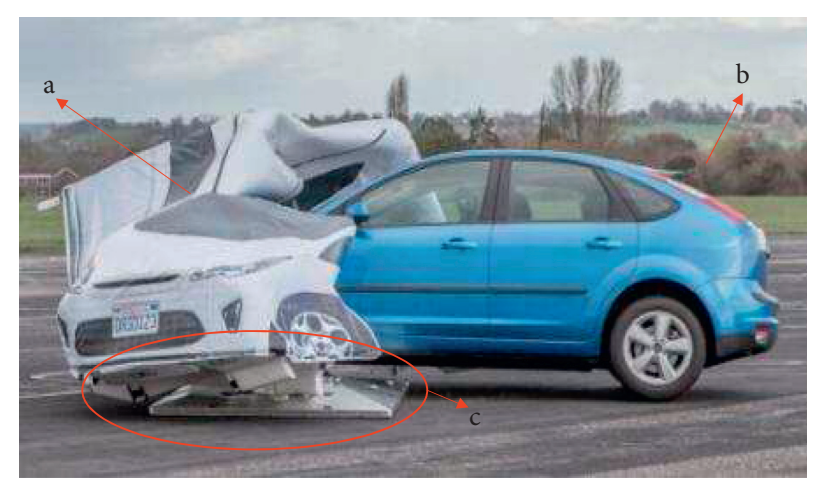

FIgURE 2: Application scenarios of testing platform vehicle: (a) GVT, (b) VUT, and (c) testing platform vehicle.

When the testing platform vehicle is overloaded, the frame contacts the ground to realize the function of overload protection; when the testing platform vehicle is running normally, we hope to have good suspension performance. For the special suspension structure proposed in this paper, the suspension structure needs to be optimized. For the multiobjective optimization problem, predecessors have done a lot of research. Optimization algorithms can be divided into two categories. The classic algorithm is linear weighting, where the weight coefficient represents the importance of each objective function, but there is no uniform standard for selecting weights [17]. The other is an optimization algorithm defined by genetic algorithm (GA), such as particle swarm optimization (PSO), artificial bee colony (ABC), differential evolution (DE), NSGA-II, multiobjective particle swarm optimization with crowding distance (MOPSO-CD), and so on. For the first type of method, Papaioannou and Koulocheris used a weighted sum method to obtain comprehensive performance indicators. Although the results obtained are better than the GA, the value of the weight coefficient is difficult to use in other systems, and it is difficult to convince people [18]. Hence, the key to combining multiobjective functions and weighting coefficients to transform multiobjective optimization problems into single-objective optimization problems is how to evaluate the design criteria of different dimensions [19]. For the second type of method, Peng took the weighted root-mean-square (RMS) value of the vertical acceleration of the sprung mass, suspension stroke, and tire deflection as the optimization target and used GA, PSO, and a genetic algorithm based on the particle swarm optimization (GA-PSO), respectively, to optimize the spring stiffness and damping, and suspension performance after 
optimization is about $20 \%$ higher than before optimization [20]. Kanarachos et al. [21] proposed a new contrast-based fruit fly optimization algorithm for the phenomenon that GA and PSO are easy to fall into local optimality. Compared with GA and PSO, the optimization result effectively reduces the peak body acceleration. In the second method, NSGA-II is widely used in multiobjective optimization scenarios of vibration systems, not only in automobile suspension systems but also in vibration isolation and mitigation (VIM) systems [22]. Gadhvi et al. analyzed the application of NSGA-II, strength Pareto evolutionary algorithm (SPEA2), and Pareto envelope-based selection algorithm II (PESA-II) in semivehicle passive suspension systems. They pointed out that NSGA-II has a better optimization effect but lacks sample diversity. However, this article analyzed the characteristics of the algorithm itself, and the analysis of the suspension system is not sufficient [23]. For the full vehicle model, Fossati et al. [24] used six parameters such as stiffness and damping as optimization variables and allowed a reduction of up to $21.14 \%$ of the weighted RMS value of the driver seat vertical acceleration using the NSGA-II. In [25], the authors used NSGA-II and MOPSO-CD algorithms for multiobjective optimization to optimize comfort and health standards. The performance before and after optimization is increased by 20 and $19 \%$, respectively. In addition, NSGA-II has better optimization results than MOPSO-CD, but it requires a longer calculation time. For the time-consuming problem of NSGAII, Papaioannou et al. proposed KEMOGA in optimizing the ride comfort of the passenger vehicle, which combined the sorting algorithm (KE) with the multiobjective genetic algorithm (MOGA) to reduce the optimization time [26]. In addition, there are some relatively novel optimization algorithms. A layered optimization method was proposed based on the GA algorithm, and the optimization variables were designed as the chassis layer and the cabin layer. Before optimizing the cabin layer, the parameters of the chassis layer need to be optimized, which can simultaneously control the target from the perspective of the transfer path. The optimization effect of reducing vehicle acceleration by $18 \%$ is achieved [27]. In addition, scholars have used ADAMS/Car software to optimize the design of the suspension hardpoints and bushing stiffness and pointed out that positions of the suspension hardpoints and bushing stiffness have a significant influence on vehicle minimum time handling and stability [28]. Suspension optimization is mostly for passenger vehicles, and the main problem to be solved is to improve ride comfort. There are few suspension optimizations for suspension installation position analysis and special application scenarios, especially the low-chassis testing platform mentioned in this article. According to previous studies, although the NSGA-II takes a long time to calculate, its good optimization performance is better than other algorithms. This article will use NSGA-II to optimize the suspension performance of the testing platform vehicle with multiple objectives.
The main contributions of this paper are as follows:

(1) This paper proposes a unique suspension construction for ultralow-chassis testing platforms. In addition to good maneuverability, the innovative ultralow-chassis testing platform vehicle employs a unique suspension system, which enhances the overload protection of the system. This unique "foldable arm suspension" structure is simple and does not require any additional power devices to ensure overload protection of the suspension. This is particularly important for the scene of the ultralowchassis testing platform vehicle.

(2) The field experiment verified the correctness of the suspension model. The experiment was divided into a static experiment and a dynamic experiment. The field experiment of the testing platform vehicle verified the relationship between the displacement of the vehicle body and the load. The maximum deviations of static experiment and dynamic experiment were 2 and $9.9 \%$, respectively.

(3) Using NSGA-II to optimize the suspension parameters, the results show that a certain optimization effect has been achieved under different loads. The optimization results prove the feasibility of NSGA-II and provide guidance for optimizing the suspension of the testing platform vehicle with ultralow chassis.

The paper is organized as follows. First, a novel ultralow chassis testing platform vehicle with a retractable suspension is proposed that can carry GVT and can also protect the testing platform vehicle to the greatest extent when it is crushed in Section 2. Second, a quarter vehicle model of the testing platform vehicle system was established, and two indexes of dynamic tire deflection and displacement of vehicle body were put forward as the criteria for evaluating the suspension performance in Section 3. In Section 4, a field experiment was carried out to verify the correctness of the vehicle model and analyze the simulation and experimental results. In Section 5, the NSGA-II is used to optimize the suspension structure parameters with multiple objectives, which provides a reference for future research. At last, conclusions are given in Section 6.

\section{Structure and Working Principle}

As shown in Figure 3, the testing platform vehicle consists of a bodyshell, loadable frame, steering system, suspension system, and power system. Considering the working environment of the bodyshell, the bodyshell needs to carry a relatively large load, and the structure of built-in ribs is adopted to increase the carrying capacity of the bodyshell; the loadable frame adopts an integrated welding process to achieve the purpose of increasing the carrying capacity; the steering system is based on the Ackerman steering 

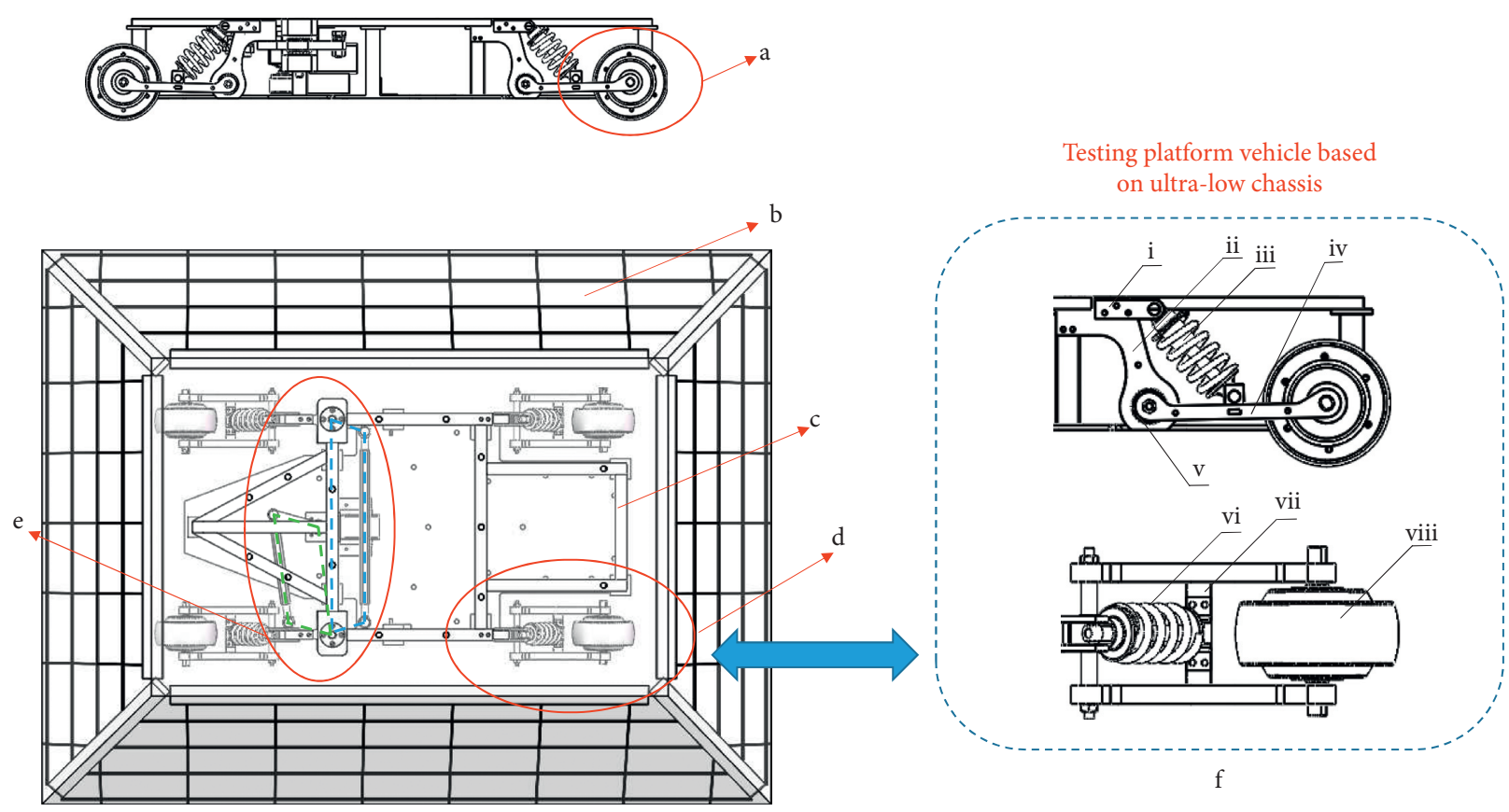

FiguRE 3: Structure of testing platform vehicle: (a) power system; (b) bodyshell; (c) loadable frame; (d) suspension system; (e) steering system; and (f) suspension system detailed display diagram with (i) mounting lugs, (ii) load-bearing arm, (iii) shock absorber, (iv) rocker, (v) double-row angular contact ball bearings, (vi) spring, (vii) supporting crossarm, and (viii) wheel.

trapezoidal, with simple and reliable structure; the power system adopts distributed drive technology, which is composed of four sets of hub motors and four sets of drivers, which can realize time-sharing drive; and the suspension system consists of a so-called foldable arm suspension.

The working state of the testing platform vehicle is divided into three types: no-load state, working state, and touchdown state. The suspension system only needs to bear the weight of the vehicle body in the no-load state. At this time, the spring is slightly contracted; the working state is that the GVT (about $110 \mathrm{~kg}$ ) is fixed on the shell of the testing platform vehicle, and the spring is further compressed. The testing platform vehicle can carry the GVT to move according to the path required by the test; the touchdown state means that the VUT can easily pass the testing platform vehicle during the test if a collision occurs. Even if the GVT is damaged, the VUT will not be damaged, ensuring the driver's life safety. The working process of the foldable arm suspension of the testing platform vehicle is shown in Figure 4.

The structure of a single foldable arm suspension is shown in Figure 3(f): the main body comprises two mounting lugs, two rocker arms, one load-bearing arm, one spring, one shock absorber, and one supporting crossarm. The spring is an elastic element; the shock absorber is a damping element; and the spring and the shock absorber are installed together concentrically, making the structure simpler and more compact. The spring and shock absorber are installed between the mounting lugs and the supporting crossarm. When the suspension is compressed, the angle between the load-bearing arm and the rocker arm will change. The rocker arm will rotate around the double-row angular contact ball bearings at the lower part of the load-bearing arm and then compress the spring to achieve the desired effect of work. When the testing platform vehicle is rolled, the effect shown in Figure 4 will appear. At this time, the impact force is mainly absorbed by the load-bearing arm and the frame, which protects the wheels from damage and improves the overall reliability of the testing platform vehicle. A prototype as shown has been manufactured to verify the performance of the testing platform vehicle further, as shown in Figure 5. The scale of the platform vehicle is 1:1.

\section{Model Building and Simulation}

3.1. Suspension Statics and Simulation. Based on theoretical mechanics, the statics analysis of the equilibrium position of the half-vehicle model of the testing platform vehicle is carried out. Figure 6 is the force analysis diagram of the testing platform vehicle.

By carrying out the force analysis of the testing platform vehicle, the following equations can be obtained:

$$
\begin{aligned}
F_{1}-\left(\frac{m_{1}+m_{2}}{4}\right) g & =0, \\
F_{k} \cos \beta+F_{y}-\frac{m_{2} g}{4} & =0, \\
F_{k} \sin \beta-F_{x} & =0, \\
F_{k} \sin \theta_{2} a-\left(\frac{m_{1}+m_{2}}{4}\right) g L_{a} \sin \theta & =0,
\end{aligned}
$$

where $F_{1}$ refers to the ground reaction force received by a single wheel of the testing platform vehicle; $m_{1}$ and $m_{2}$ refer to sprung mass and unsprung mass, respectively; $F_{k}$ refers to spring force; $F_{x}$ and $F_{y}$ refer to force of hinge $\mathrm{A}$ on $m_{1}$ in the direction $x$ and $y$, respectively; $\beta$ refers to the angle between 
(a)

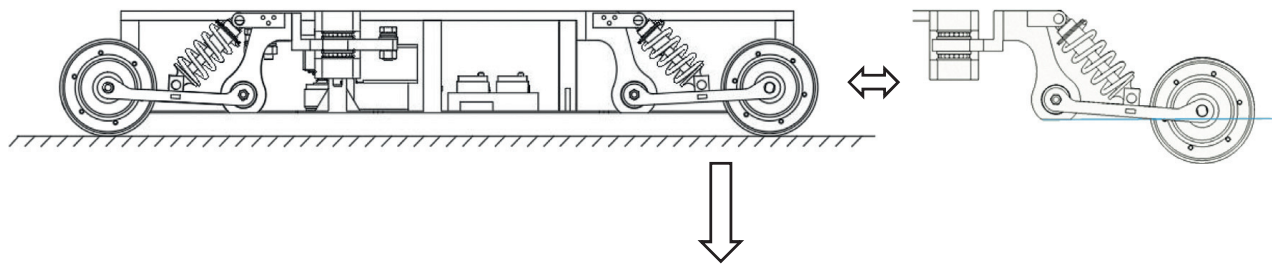

(b)

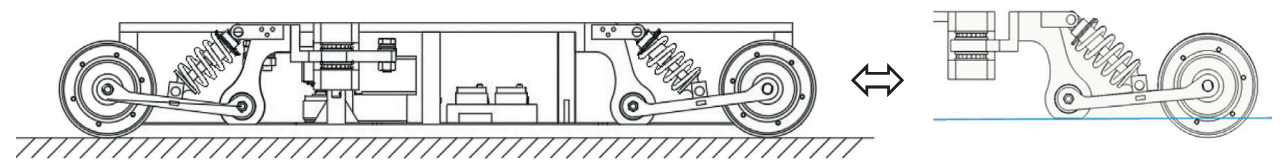

(c)
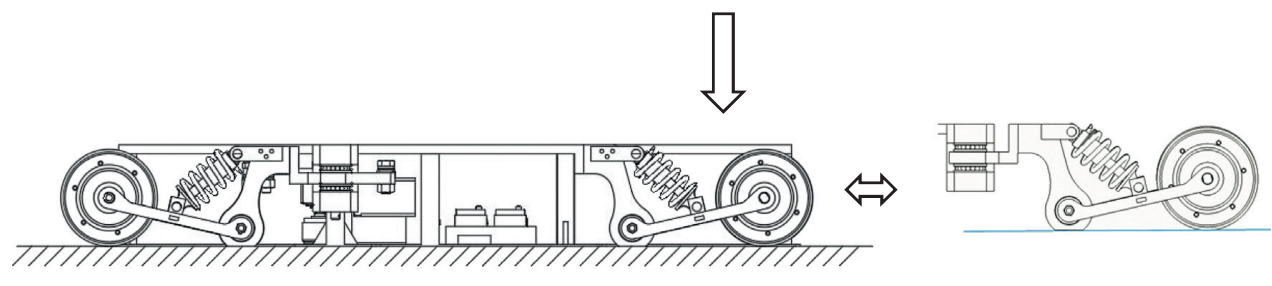

Figure 4: Working process of foldable arm suspension of testing platform vehicle: (a) no-load state, (b) working state, and (c) touchdown state.

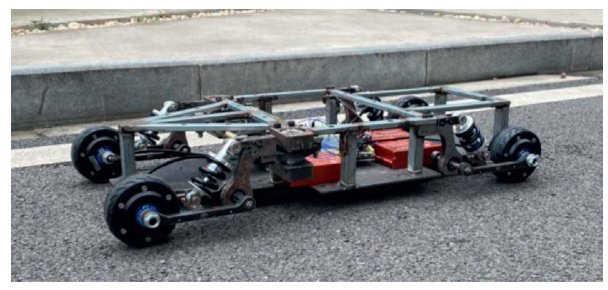

FIGURe 5: Prototype.

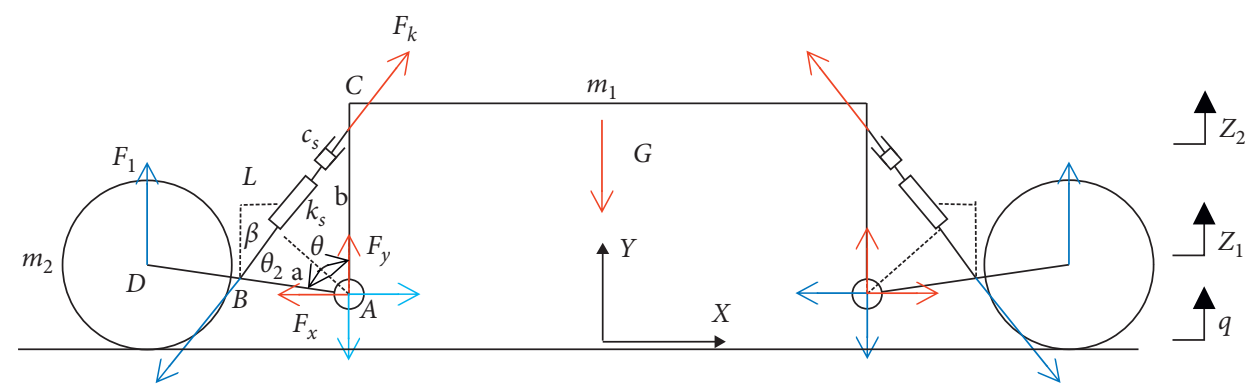

FIGURE 6: Force analysis diagram of the testing platform vehicle.

$\mathrm{BC}$ and the vertical direction; $a$ and $L_{a}$ refer to the length of $\mathrm{AB}$ and $\mathrm{AD}$, respectively; $\theta$ and $\theta_{2}$ refer to $\angle \mathrm{CAB}$ and $\angle \mathrm{ABC}$, respectively.

At the same time, the force of the spring conforms to Hooke's law as follows:

$$
F_{k}=k_{s}\left(L_{0}-L\right)
$$

where $L_{0}$ refers to the original length of spring, $L$ refers to the length in spring equilibrium position, and $k_{s}$ refers to spring stiffness.

Finally, according to the geometric relationship, the following equation can be obtained:

$$
\left\{\begin{array}{l}
\theta=\cos ^{-1} \frac{a^{2}+b^{2}-L^{2}}{2 a b}, \\
\theta_{2}=\cos ^{-1} \frac{a^{2}+L^{2}-b^{2}}{2 a L}, \\
\beta=\pi-\theta-\theta_{2} .
\end{array}\right.
$$

3.2. Suspension Dynamics. The quarter suspension dynamics model of the test platform car is shown in Figure 7, where $m_{1}$ 
and $m_{2}$ refer to sprung mass and unsprung mass, respectively; $L_{a}$ refers to the length of $\mathrm{AD} ; k_{s}$ refers to spring stiffness; $c_{s}$ refers to damping coefficient of the damper; $\lambda$ refers to $a / L_{a}$, which range is $0.3 \sim 0.7$ (determined by the installation relationship); $q$ refers to road roughness; $k_{t}$ refers to tire stiffness; $z_{2}$ and $z_{1}$ refer to the vertical displacement of the vehicle body and the vertical displacement of the tire, respectively; $J_{g x}$ refers to the moment of inertia of wheel and rocker arm around hinge $A$; and $F_{y}$ refers to force of hinge $\mathrm{A}$ on $m_{1}$ in the direction $y$.

$$
\begin{aligned}
& m_{2} \ddot{z}_{2}=k_{s}(1-\lambda)\left(z_{1}-z_{2}\right)+c_{s}(1-\lambda)\left(\dot{z}_{1}-\dot{z}_{2}\right)+F_{y} \\
& m_{1} \ddot{z}_{1}=k_{t}\left(q-z_{1}\right)-k_{s}(1-\lambda)\left(z_{1}-z_{2}\right) \\
& \quad-c_{s}(1-\lambda)\left(\dot{z}_{1}-\dot{z}_{2}\right)-F_{y} \\
& {\left[\begin{array}{rl}
\left.-k_{s}(1-\lambda)\left(z_{1}-z_{2}\right)-c_{s}(1-\lambda)\left(\dot{z}_{1}-\dot{z}_{2}\right)\right] \\
\times & L_{1}\left(m_{1} \ddot{z}_{2}-m_{1} \ddot{z}_{1}\right) \times L_{2}=J_{g x} \ddot{\theta} \\
& \left\{\begin{array}{l}
\dot{\theta}=\frac{\left(z_{2}-z_{1}\right)}{a} \\
L_{1}=L_{a} \lambda \sin \theta \\
L_{2}=L_{a} \sin \theta
\end{array}\right.
\end{array}\right.}
\end{aligned}
$$

According to Newton's second law, the following dynamic differential equations of the quarter suspension system can be obtained:

3.3. Road Excitation and Evaluation Indicators. It can be seen from the above differential equation that for different inputs, each indicator variable will have different results. It can be considered that the road surface roughness is random, which can be abstracted as white noise that satisfies certain conditions. The filter performs appropriate transformation and fits the random road surface with specified spectral characteristics [29], which satisfies the following equation:

$$
\dot{q}(t)=-2 \pi f_{0} q(t)+2 \pi \sqrt{G_{0}} v w(t),
$$

where $G_{0}$ refers to road roughness coefficient, $v$ refers to testing platform vehicle driving speed, $w(t)$ refers to Gaussian white noise signal with zero mean, and $f_{0}$ refers to lower stopband edge frequency.

Most of the suspension evaluation indexes of traditional vehicles use body acceleration, suspension dynamic deflection, and tire dynamic load as evaluation indexes [30, 31].

Among them, body acceleration mainly affects the comfort of passengers, but for the testing platform vehicle, without a driver, the importance of body acceleration has decreased. Since the ground clearance of the testing platform vehicle is very small, the displacement of the vehicle body will be particularly important for the testing platform vehicle; in addition, due to the small tire size, the grounding of the tire is also important for the testing platform vehicle. Considering comprehensively, the root-mean-square values of the displacement of the vehicle body and the dynamic tire deflection are taken as the evaluation index of the suspension of the test platform vehicle, as follows:

$$
\begin{aligned}
& f_{1-\mathrm{RMS}}=\sqrt{\frac{\sum_{i=1}^{N} f_{1, i}\left(k_{s}, \lambda, c_{s}\right)^{2}}{N}}, \\
& f_{2-\mathrm{RMS}}=\sqrt{\frac{\sum_{i=1}^{N} f_{2, i}\left(k_{s}, \lambda, c_{s}\right)^{2}}{N}},
\end{aligned}
$$

where $f_{1}$ refers to $z_{2}(t), f_{2}$ refers to $z_{1}(t)-q(t)$, and $f_{1-\mathrm{RMS}}$ and $f_{2-\mathrm{RMS}}$ refer to RMS of displacement of the vehicle body and dynamic tire deflection, respectively.

\section{Simulation and Experimental Verification}

4.1. Dynamic Simulation Based on MATLAB. The structural parameters of the testing platform vehicle are limited by the minimum ground clearance of the VUT, the mass of the GVT, and the size of the testing platform vehicle wheels, so the parameters shown in Table 1 are defined in the design stage.

To verify the performance of the suspension, it is necessary to select the body parameters initially. The variables involved in the simulation and the parameters of the testing platform vehicle are shown in Table 2 .

Considering the minimum ground clearance of VUT and the standard mass of GVT, according to the above statics equations, the initial spring stiffness is $130,000 \mathrm{~N} / \mathrm{m}$, and the damping coefficient is $2,000 \mathrm{~N} /(\mathrm{m} / \mathrm{s})$.

A simulation model is built in the Simulink software based on the differential equations of the quarter passive suspension of the testing platform vehicle. The simulation results of the dynamic tire deflection, displacement of the vehicle body, and tire acceleration in the time domain are shown in Figures 8-10.

Figure 8 is the relationship between the dynamic tire deflection with time under the B-level road excitation. The maximum value is $4 \mathrm{~mm}$; the minimum value is $-3.8 \mathrm{~mm}$; and the negative value means that the tire is not in contact with the road surface. The root-mean-square (RMS) value of the dynamic tire deflection is $2.09 \mathrm{~mm}$, and the maximum ground clearance of the tire is $3.8 \mathrm{~mm}$, indicating that the grounding performance of the testing platform vehicle is good. The relationship curve of the displacement of the vehicle body with time under the B-level road excitation is shown in Figure 9. The fluctuation range of the displacement of the vehicle body is about $13 \mathrm{~mm}$. The RMS value of the displacement of the vehicle body is $3.12 \mathrm{~mm}$. Figure 10 shows the relationship of the body acceleration of the testing platform vehicle over time. From the curve, it can be seen that the range of the body acceleration of the test platform car is -7 to $7 \mathrm{~m} / \mathrm{s}^{2}$, which is much higher than the body acceleration value of the passenger vehicle. The reason is that the type of suspension mentioned in the article needs to ensure that the car has a low body height when there is no load. It needs to carry $110 \mathrm{~kg}$ under normal working conditions. Therefore, greater suspension stiffness is required, which is also a unique feature of this suspension. The test platform vehicle mentioned in the 


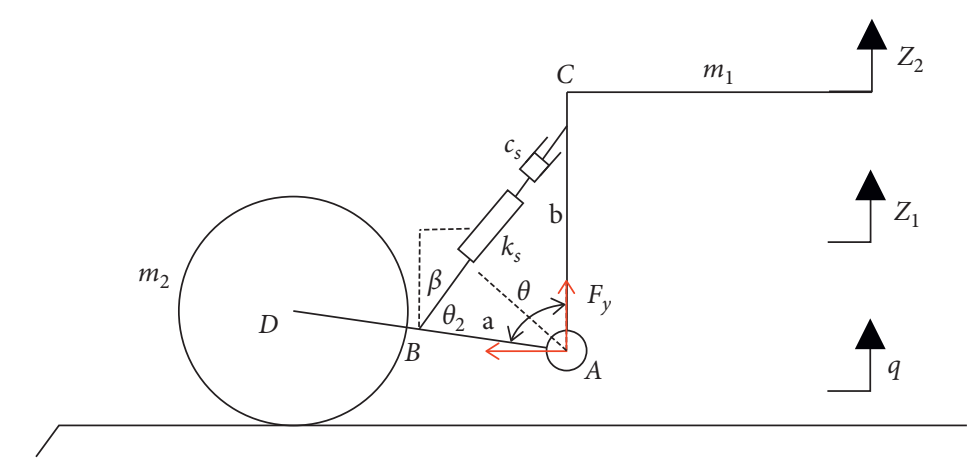

FiguRE 7: Quarter suspension dynamics model of the testing platform vehicle.

TABLE 1: Structural parameters of the testing platform vehicle.

\begin{tabular}{lcc}
\hline Parameters & Unit & Value \\
\hline Minimum ground clearance of VUT & $\mathrm{mm}$ & 135 \\
Mass of GVT & $\mathrm{kg}$ & 110 \\
Mass of touch the ground & $\mathrm{kg}$ & $>250$ \\
Size of tire diameter & $\mathrm{mm}$ & 108 \\
\hline
\end{tabular}

article is a nonpassenger vehicle, so there is no requirement for its comfort. The body acceleration does not need to be considered too much.

4.2. Field Test. To verify the feasibility of the solution and the correctness of the simulation model, a field test was carried out. The experimental platform is shown in Figure 11. This experiment is divided into the static and the dynamic experiments. The static experiment mainly explores the relationship between the ground clearance of the test platform vehicle and the load; the dynamic experiment mainly explores the suspension performance of the testing platform vehicle under different loads, including body acceleration, displacement of the vehicle body, and dynamic tire deflection.

4.3. Results and Discussion. The verification of the simulation results and the experimental data in terms of the vehicle body displacement is shown in Figure 12.

In the static load experiment, when the testing platform vehicle has no load, the simulation result of the testing platform vehicle's ground clearance is $137 \mathrm{~mm}$. In contrast, the experimental result is $134.26 \mathrm{~mm}$, with a difference of $2.74 \mathrm{~mm}$ (the error is $2 \%$ ). When the load is 230 and $240 \mathrm{~kg}$, both the experimental and simulation results of the vehicle ground clearance reach $110 \mathrm{~mm}$. The testing platform vehicle touches the ground, and the suspension and wheels are protected. When the load is 50 and $170 \mathrm{~kg}$, the simulation and experimental results have large deviations (errors are 1.3 and $1.9 \%)$. Hence, the simulation results are basically consistent with the experimental results. Due to the quality of the test equipment and processing errors, the experimental and simulation results have a deviation, but the variation is in a lower range. Thus, the model can be used for the following analysis.

The dynamic experiment is divided into three groups. The load of the testing platform vehicle is 20,60 , and $140 \mathrm{~kg}$, respectively, to simulate the mass of the pedestrian model, the electric vehicle model, and the GVT model. Figures 13-15 show the experimental and simulation results under 20,60 , and $140 \mathrm{~kg}$, respectively.

When the spring stiffness is $130,000 \mathrm{~N} / \mathrm{m}$ and the damping coefficient is $2,000 \mathrm{~N} /(\mathrm{m} / \mathrm{s})$, it can be found in Figures 13-15 that the load has little effect on the displacement of the vehicle body of the testing platform vehicle, and the fluctuations are within $8 \mathrm{~mm}$. This was also confirmed in the field test results. When the load is $20 \mathrm{~kg}$, the mean square errors of the simulation and experimental results of the height of the testing platform vehicle are 1.03 and $0.97 \mathrm{~mm}$, respectively, with an error of $5.8 \%$. In the case of $60 \mathrm{~kg}$, the mean square errors of the simulation and experimental results of the height of the testing platform vehicle are 2.21 and $2.43 \mathrm{~mm}$, respectively, with an error of $9.9 \%$. For a $140 \mathrm{~kg}$ load, the simulation and experimental results of the height of the testing platform vehicle are 1.77 and $1.70 \mathrm{~mm}$, respectively, with an error of $3.9 \%$. Vehicle body height of the testing platform vehicle is $133.28,129.15$, and $121.25 \mathrm{~mm}$ when the weight is 20,60 , or $140 \mathrm{~kg}$, respectively. Based on static modeling, vehicle heights are 133.80, 128.88, and $119.91 \mathrm{~mm}$ when the load is 20,60 , or $140 \mathrm{~kg}$, respectively. The simulation results are highly consistent with the experimental data, with a maximum deviation of $1.1 \%$.

The field test proves the correctness of the mathematical model and the simulation model, which can better reflect the performance of the real vehicle and show that this solution can better meet the operating conditions of the testing platform vehicle. The initial height of the testing platform vehicle is relatively small, and the vehicle speed selected in the simulation is only $3 \mathrm{~m} / \mathrm{s}$. These are the reasons for the maximum deviation of $1.1 \%$.

\section{Optimization and Analysis}

5.1. Parameter Sensitivity Analysis. According to the dynamic model of the testing platform vehicle, analysis of the suspension system's major parameters was carried out before optimizing suspension settings. We need to keep the installation position settings the same but investigate the 
TABLE 2: Structural parameters of the testing platform vehicle.

\begin{tabular}{|c|c|c|c|}
\hline Parameters & Symbol & Unit & Value \\
\hline Unsprung mass & $m_{1}$ & $\mathrm{~kg}$ & 135 \\
\hline Sprung mass & $m_{2}$ & $\mathrm{~kg}$ & 12 \\
\hline Suspension stiffness & $k_{s}$ & $\mathrm{~N} / \mathrm{m}$ & 130,000 \\
\hline Damping coefficient & $c_{s}$ & $\mathrm{~N} /(\mathrm{m} / \mathrm{s})$ & 2,000 \\
\hline Installation location parameters & $\lambda$ & & 0.5 \\
\hline Tire stiffness & $k_{t}$ & $\mathrm{~N} / \mathrm{m}$ & 50,000 \\
\hline Length of the lower rocker arm & $L_{a}$ & $\mathrm{~m}$ & 0.15 \\
\hline Moment of inertia of wheel and rocker arm around A hinge & $J_{g x}^{u}$ & kg.m ${ }^{2}$ & 0.06 \\
\hline Lower stopband edge frequency & $f_{0}$ & $\mathrm{~Hz}$ & 0.01 \\
\hline Road roughness coefficient & $G_{0}$ & $\mathrm{~m}^{-3}$ & 0.000064 \\
\hline Testing platform vehicle speed & $v$ & $\mathrm{~m} / \mathrm{s}$ & 3 \\
\hline
\end{tabular}

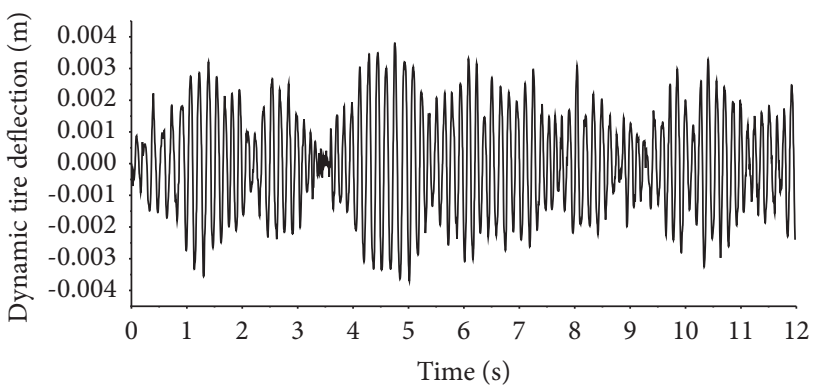

Figure 8: Time-domain plot of the dynamic tire deflection.

sensitivity results of the variation of the suspension stiffness (Figures 16 and 17).

According to Figures 16 and 17, different suspension stiffness and installation position parameters will affect the height of the testing platform vehicle. When the installation position parameter is 0.5 , the suspension stiffness changes from 110,000 to $140,000 \mathrm{~N} / \mathrm{m}$. When the load is $240 \mathrm{~kg}$, the testing platform vehicle's height is 107.95, 110.06, 111.02, 111.91 , and $113.53 \mathrm{~mm}$, and the variance is $4.3345 \mathrm{~mm}^{2}$. When the suspension stiffness is maintained at $120,000 \mathrm{~N} / \mathrm{m}$, the installation position parameter changes from 0.3 to 0.7 . When the load is $240 \mathrm{~kg}$, the vehicle height is $97.81,108.14$, $110.06,113.27$, and $116.38 \mathrm{~mm}$, and the variance is $49.9439 \mathrm{~mm}^{2}$. According to the variance, it can be obtained that the installation position parameter is more sensitive to the vehicle height of the test platform than the suspension stiffness. The reason is that the geometry of the suspension structure of the test platform vehicle changes during the working process, and the geometry of the no-load state will significantly affect the suspension performance.

5.2. Suspension Optimization. This article used the NSGA-II to optimize the suspension parameters. The NSGA-II is a multiobjective genetic algorithm used commonly, which has the advantages of fast running speed and good solution set convergence. It is often used in multiobjective optimization [32]. The algorithm uses a nondominated sorting algorithm to classify population fitness, uses individual crowding distance to ensure population diversity, selects parent population through elite strategy, and generates offspring population through genetics and mutation [33]. The NSGA-II is used in the

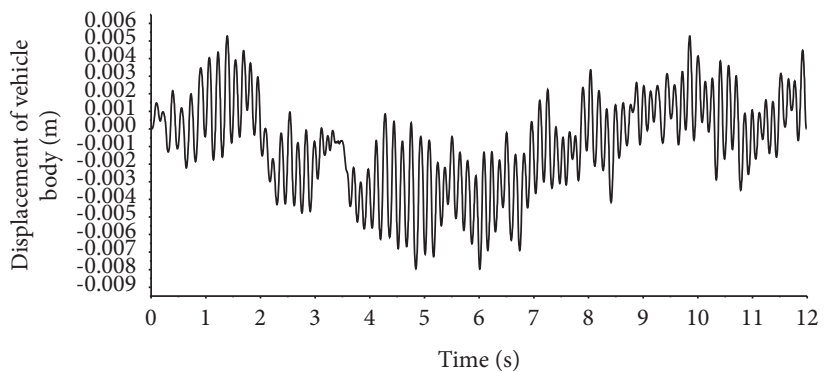

Figure 9: Time-domain plot of the vehicle body displacement.

optimization: the population size is 600; the first generation population is obtained through random sampling; the binary crossover algorithm is used, and the crossover probability is $90 \%$; the polynomial mutation algorithm is used; the mutation probability is $1 / 3$; and the termination condition is 500 iterations. The flow chart of the NSGA-II is shown in Figure 18.

For the testing platform vehicle, the RMS values of the displacement of the vehicle body and dynamic tire deflection are used as the suspension evaluation index. Suspension spring stiffness $\left(k_{s}\right)$, shock absorber damping coefficient $\left(c_{s}\right)$, and installation position parameters $\lambda$ as parameter variables are taken. The optimization method satisfies the mathematical relationship as given in equation (14).

$$
\left\{\begin{array}{l}
\min f\left(k_{s j}, \lambda_{j}, c_{s j}\right), \\
f_{1-\mathrm{RMS}}=\sqrt{\frac{\sum_{i=1}^{N} f_{1, i}\left(k_{s j}, \lambda_{j}, c_{s j}\right)^{2}}{N}}, \quad j=1, \ldots, m, \\
f_{2-\mathrm{RMS}}=\sqrt{\frac{\sum_{i=1}^{N} f_{2, i}\left(k_{s j}, \lambda_{j}, c_{s j}\right)^{2}}{N}}, \quad j=1, \ldots, m, \\
\left(k_{s j}, \lambda_{j}, c_{s j}\right) \in\left(K_{s j}, \Lambda_{j}, C_{s j}\right),
\end{array}\right.
$$

where $\left(K_{s j}, \Lambda_{j}, C_{s j}\right)$ refers to the ranges of suspension spring stiffness $\left(k_{s}\right)$, shock absorber damping coefficient $\left(c_{s}\right)$, and installation position parameter $\lambda$. Considering the suspension working conditions and installation restrictions comprehensively, the following ranges are initially set for the suspension stiffness, shock absorber damping, and installation position parameters: 


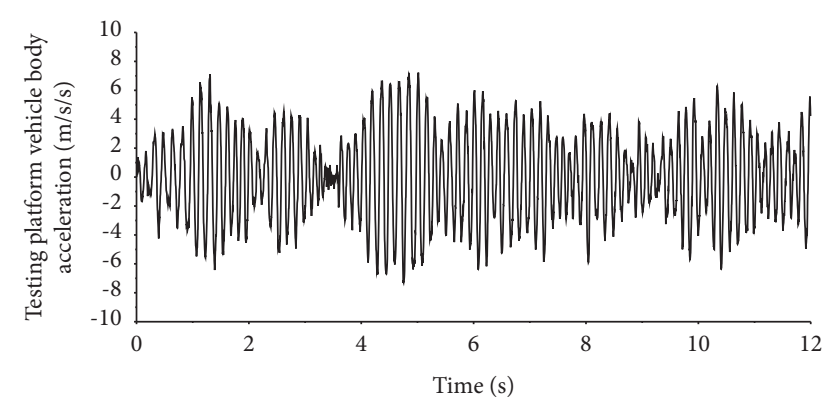

Figure 10: Time-domain plot of the vehicle body acceleration. (a)

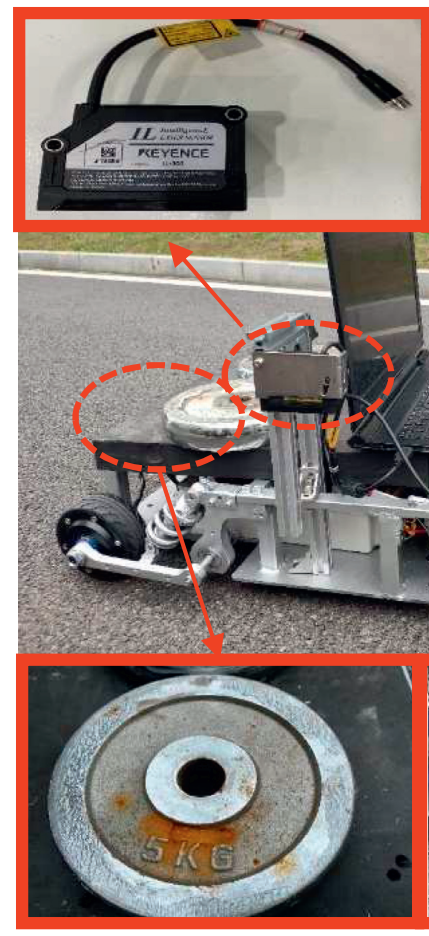

(c) (b)

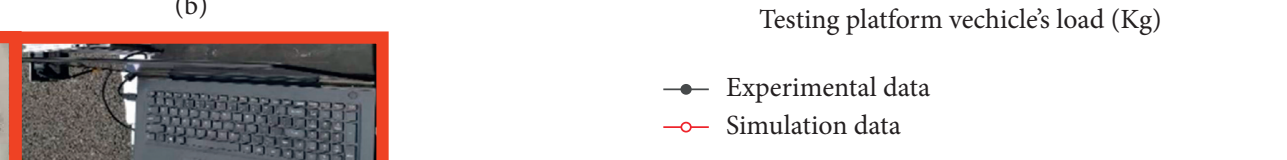

FIGURE 12: Comparison of the simulations and experiments of the vehicle body's height versus the vehicle loading conditions.

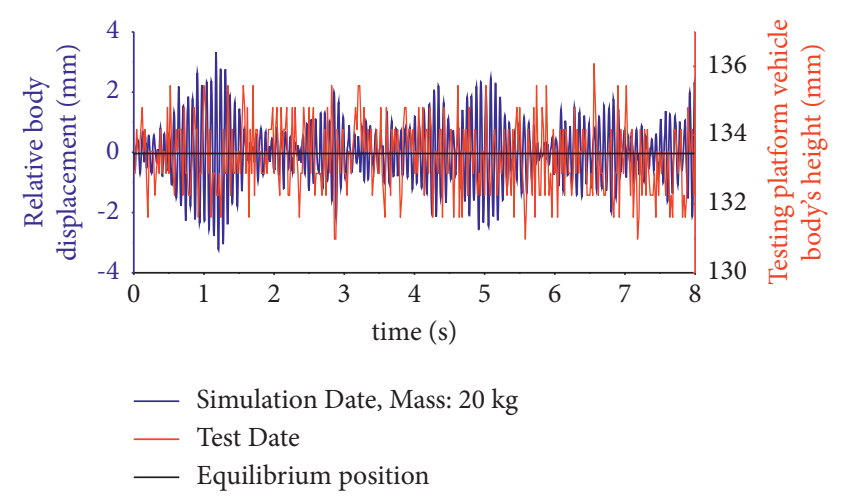

FIGURE 13: Test and simulation time-domain results of the vehicle's body height and relative displacement under $20 \mathrm{~kg}$ load.

between them, and the ideal suspension stiffness, damper damping coefficient, and installation location parameters can be easily obtained. The suspension parameters before and after the optimization are shown in Table 3.

The optimized suspension spring stiffness $\left(k_{s}\right)$, shock absorber damping coefficient $\left(c_{s}\right)$, and installation position parameter $\lambda$ are $123785.92(\mathrm{~N} / \mathrm{m}), 1,680.94(\mathrm{~N} /(\mathrm{m} / \mathrm{s}))$, and 0.3722 , respectively. The results before and after optimization with sprung masses of 20 and $140 \mathrm{~kg}$ are shown in Table 4.

The optimized spring stiffness $\left(k_{s}\right)$, shock absorber damping coefficient $\left(c_{s}\right)$, and installation position parameter $\lambda$ are brought into the Simulink mathematical model, and the following simulation results are obtained. The dynamic tire deflection and displacement of vehicle body before and after optimization are shown in Figures 20-23, respectively. When the load is $140 \mathrm{~kg}$, the power spectral density (PSD) of the dynamic tire deflection before and after optimization is shown in Figure 24.

Figure 20 shows the time-domain dynamic tire deflection when the load is $140 \mathrm{~kg}$, while the time history of 


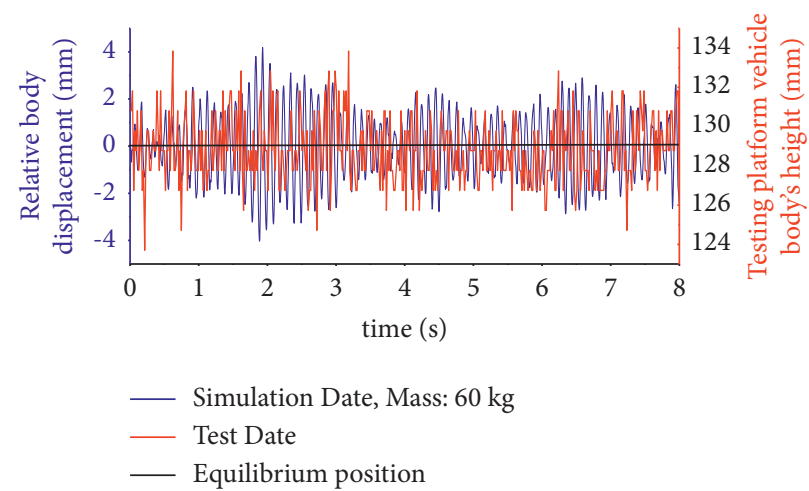

FIgURE 14: Test and simulation time-domain results of the vehicle's body height and relative displacement under $60 \mathrm{~kg}$ load.

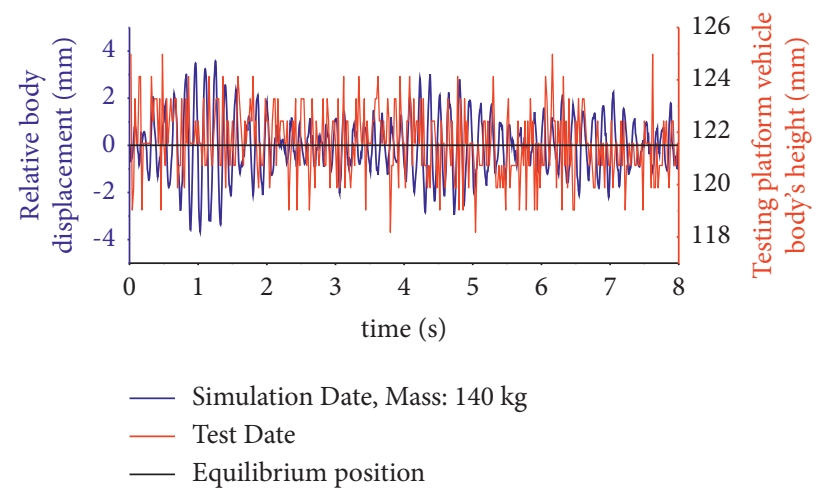

FIgURE 15: Test and simulation time-domain results of the vehicle's body height and relative displacement under $140 \mathrm{~kg}$ load.

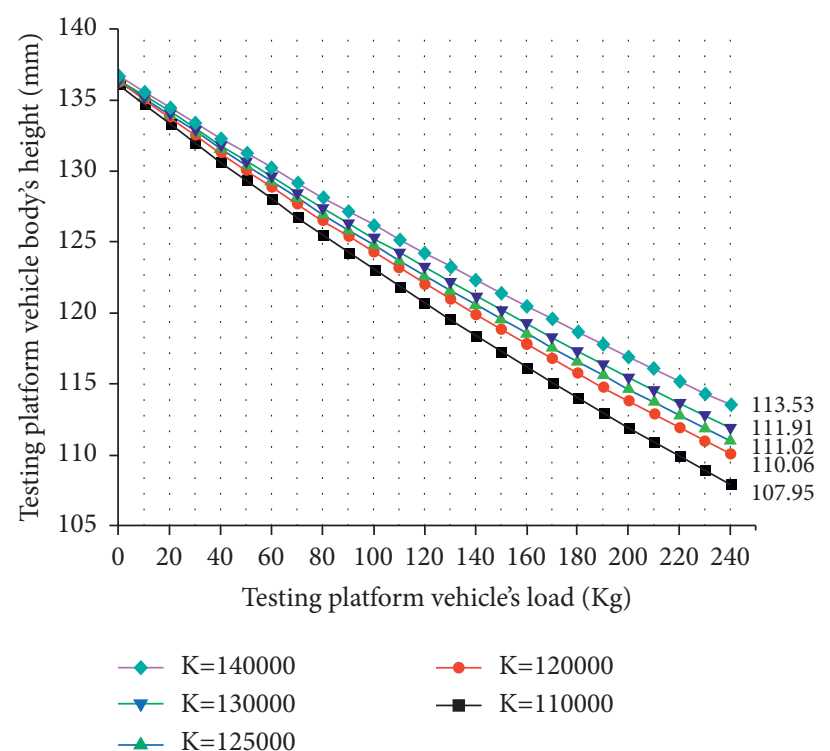

FIGURE 16: Sensitivity analysis results of the vehicle's body height versus the loading conditions under different suspension stiffness.

the displacement of vehicle body is plotted in Figure 21. Figures 22 and 23 present the time-domain dynamic tire deflection and vehicle body displacement under a load of $20 \mathrm{~kg}$, respectively. The blue curve is the suspension simulation results after optimization, and the red is the simulation results before optimization. From the simulation results, it can be obtained that the displacement of vehicle body and dynamic tire deflection have been 


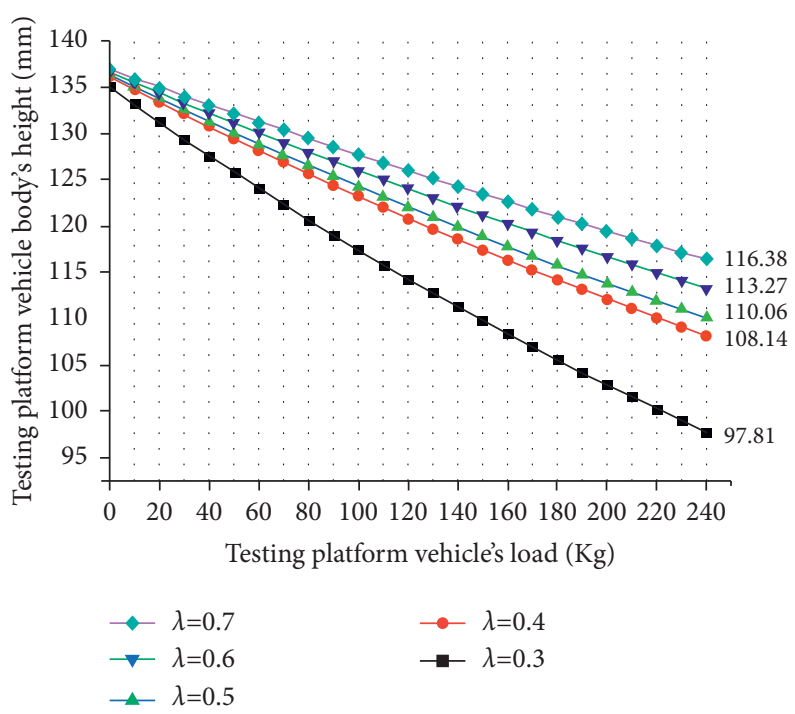

FIGURE 17: Sensitivity analysis results of the vehicle's body height versus the loading conditions under different suspension installation locations.

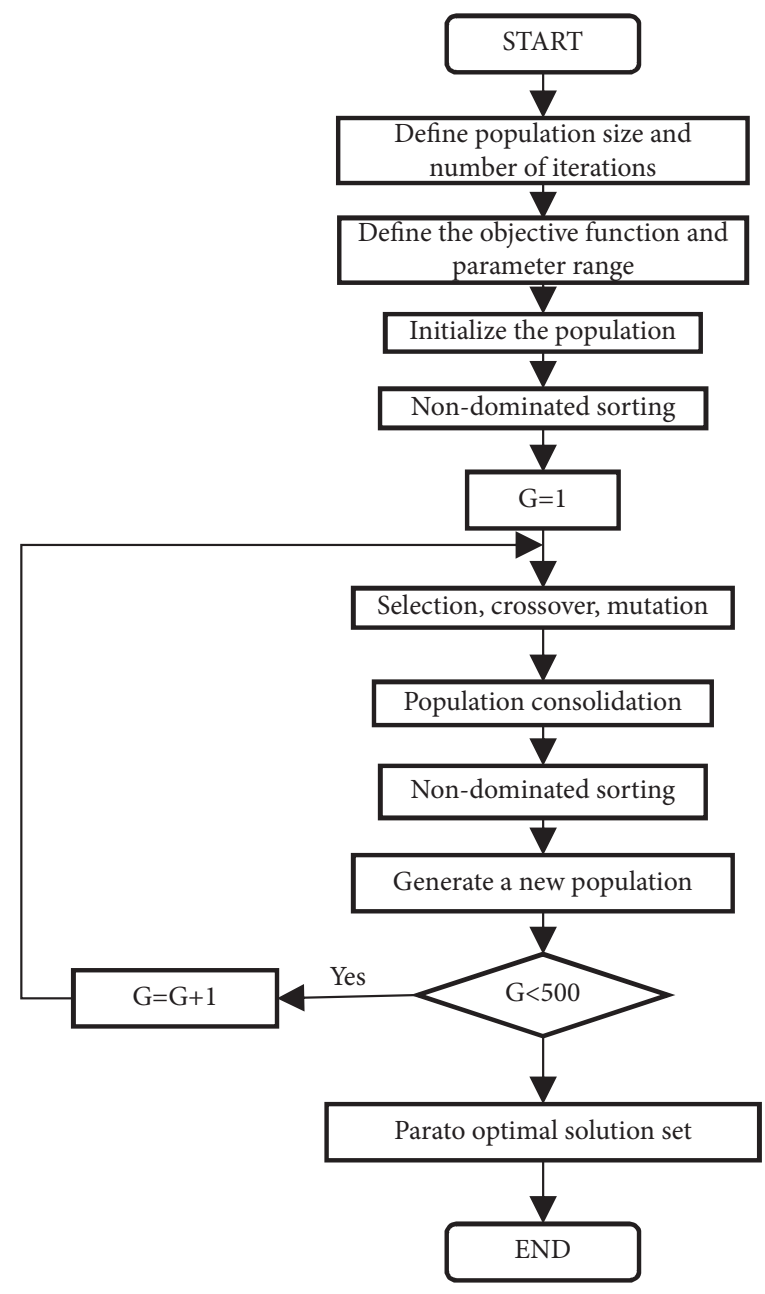

FIGURE 18: Flow chart of NSGA-II. 


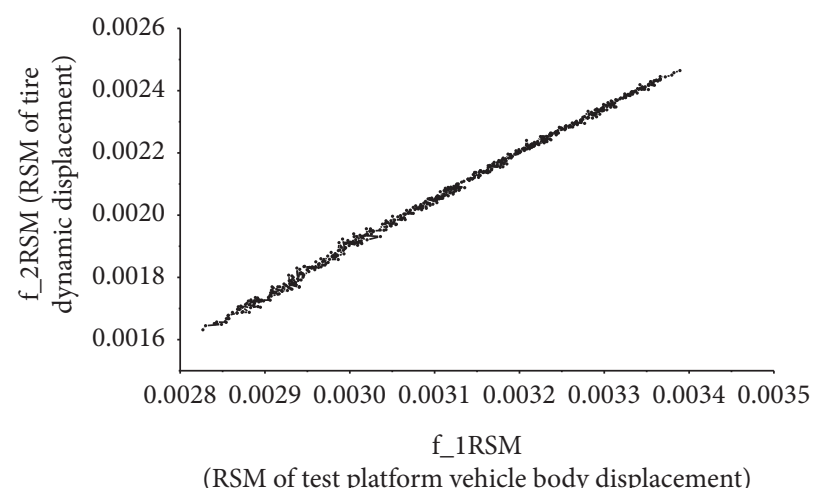

Figure 19: Plot of $f_{2-R M S}$ with $f_{1-R M S}$.

TABLE 3: Suspension parameters before and after optimization.

\begin{tabular}{lccc}
\hline Classification & Damping coefficient of shock absorber $(\mathrm{N} /(\mathrm{m} / \mathrm{s}))$ & Suspension spring stiffness $(\mathrm{N} / \mathrm{m})$ & Installation location parameter \\
\hline Initial & 2,000 & 130,000 & 0.5 \\
Optimized & $1,680.94$ & $123,785.92$ & 0.3722 \\
\hline
\end{tabular}

TABLE 4: Suspension parameters and evaluation indexes before and after optimization.

\begin{tabular}{lccc}
\hline Sprung mass $(\mathrm{kg})$ & Classification & RMS of displacement of vehicle body & RMS of dynamic tire deflection \\
\hline \multirow{2}{*}{20} & Initial & 0.00243 & 0.00087 \\
& Optimized & 0.00230 & 0.00077 \\
\hline \multirow{2}{*}{140} & Initial & 0.00312 & 0.00209 \\
& Optimized & 0.00260 & 0.00126 \\
\hline
\end{tabular}

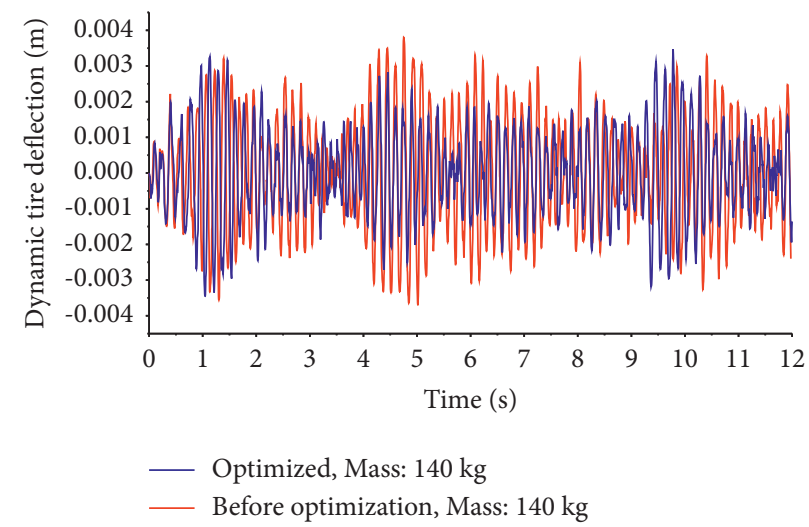

Figure 20: Comparison of the optimization results of the time-domain dynamic tire deflection at a $140 \mathrm{~kg}$ load.

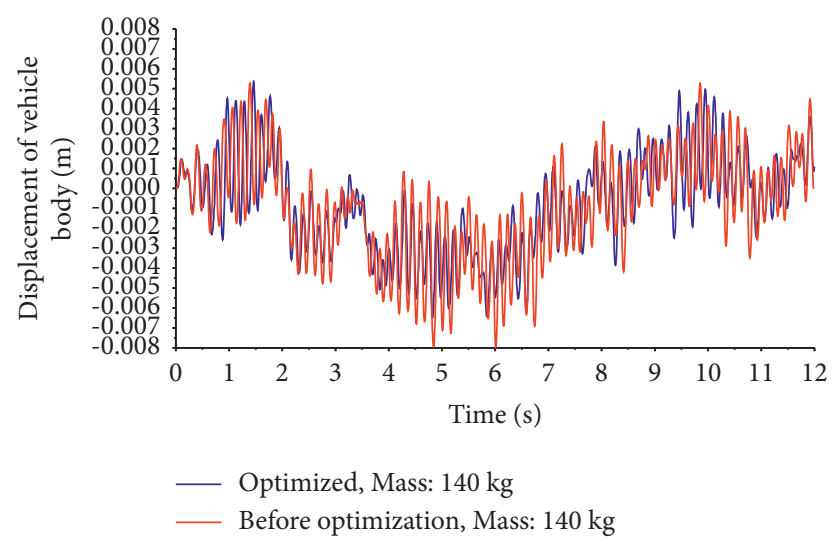

FIGURE 21: Comparison of the optimization results of the time-domain vehicle body displacement at a $140 \mathrm{~kg}$ load. 


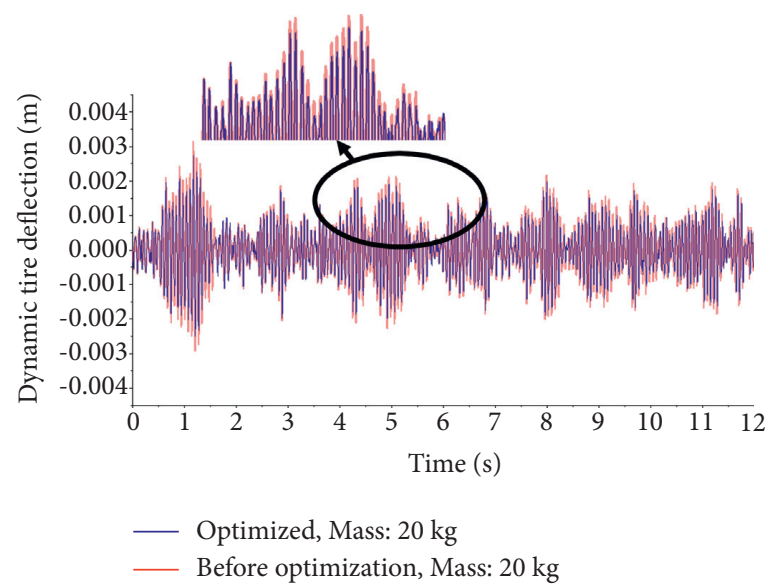

FIGURE 22: Comparison of the optimization results of the time-domain dynamic tire deflection at a $20 \mathrm{~kg}$ load.

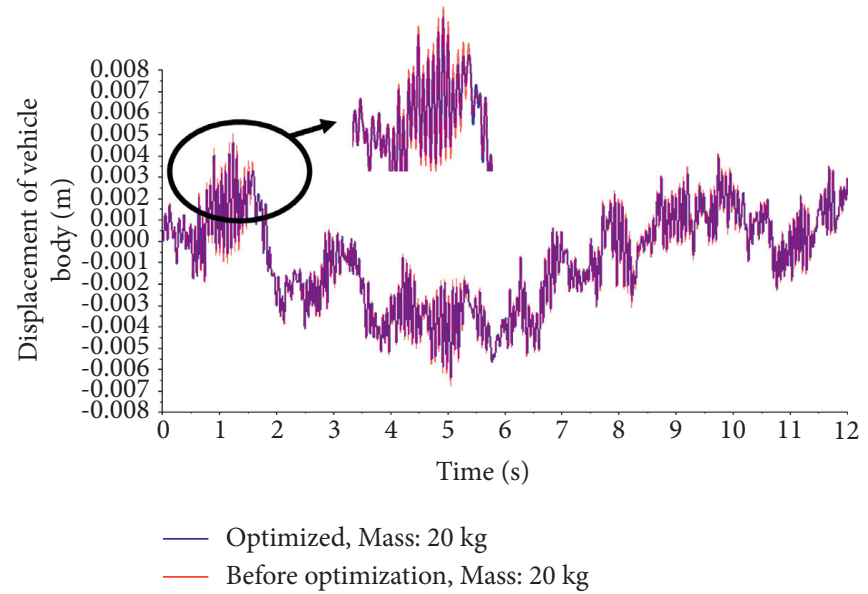

Figure 23: Comparison of the optimization results of the time-domain vehicle body displacement at a $20 \mathrm{~kg}$ load.

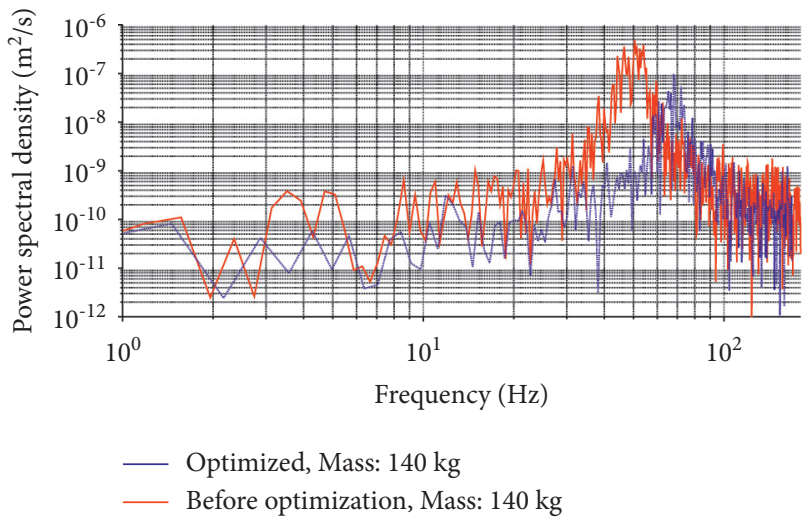

FIGURE 24: PSD of dynamic tire deflection with frequency before and after the optimization.

significantly improved when the load is $140 \mathrm{~kg}$, especially the displacement of vehicle body; when the load is $20 \mathrm{~kg}$, the optimization effect is reduced.

As shown in Table 4, when the load is $140 \mathrm{~kg}$ (working state), taking the root-mean-square value of the displacement of vehicle body and dynamic tire deflection as the evaluation index, the optimized values of $f_{1-\mathrm{RMS}}$ and $f_{2 \text {-RMS }}$ are 0.00260 and $0.00126 \mathrm{~m}$, respectively. When the load is $20 \mathrm{~kg}$ (no-load state), the optimized values of $f_{1-\mathrm{RMS}}$ and $f_{2-\mathrm{RMS}}$ are 0.0023 and $0.00077 \mathrm{~m}$, respectively.

The PSD of the dynamic tire deflection before and after optimization is shown in Figure 24. Through the 
comparison before and after optimization, at a frequency of $1-3 \mathrm{~Hz}$, the results before and after optimization are relatively close; at a frequency of $3-6 \mathrm{~Hz}$, after optimization is better than before optimization; at a frequency of $10 \sim 60 \mathrm{~Hz}$, there is a more obvious improvement. Before optimization, the frequency spectral density of dynamic tire deflection reaches a peak at a frequency of $50 \mathrm{~Hz}$; after optimization, the frequency spectral density of dynamic tire deflection reaches a peak at a frequency of $70 \mathrm{~Hz}$. It can be seen that the frequency of the peak has shifted, and the power spectral density of the peak has been significantly reduced.

\section{Conclusions}

With the promotion and popularization of ADAS systems, testing of VUTs with ADAS systems is particularly important. This paper proposes a novel ultralow-chassis testing platform vehicle with a foldable trailing arm suspension, focusing on the design and optimization of the suspension, and the following conclusions are obtained:

(1) The principle and function of the testing platform vehicle based on the ultralow chassis can better adapt to the VUT test environment, and the structure is simple and reliable.

(2) The real vehicle experiment of the testing platform vehicle verified the relationship between the displacement of vehicle body and the load. In the static experiment, the real vehicle experiment results are highly consistent with the simulation results, and the deviation between the experimental and simulation results is $2 \%$; in the dynamic experiments, using the mean square error of the displacement of vehicle body as an indicator, the maximum deviation between the experimental and simulation results is $9.9 \%$.

(3) In the simulation of sensitive parameters, it is found that the installation position parameters are more sensitive to the vehicle height of the testing platform than to the stiffness of the suspension. This is determined by the special structure of the suspension designed. The geometry of the suspension changes under different conditions.

(4) Through the NSGA-II optimization algorithm, more suitable suspension stiffness, damper damping coefficient, and installation position parameters are obtained, which are $123,785.92 \mathrm{~N} / \mathrm{m}, 1,680.94 \mathrm{Ns} / \mathrm{m}$, and 0.3722 , respectively, which provide a theoretical basis for further improvement of the actual vehicle. In addition, research shows that the root-meansquare value of the vehicle displacement of vehicle body of the test platform is positively correlated with the root-mean-square value of the dynamic tire deflection.

(5) Taking the RMS of the vehicle body displacement and the dynamic tire deflection as the evaluation indicators, the optimized suspension performance is improved compared to before the optimization under different load conditions. When the load is $20 \mathrm{~kg}$, after optimization, the root-mean-square values of the displacement of vehicle body and the dynamic tire deflection are increased by 16.66 and $39.71 \%$, respectively. When the load is $140 \mathrm{~kg}$, after optimization, the root-mean-square values of the displacement of vehicle body and the dynamic tire deflection are increased by 5.34 and $11.49 \%$, respectively.

In this study, the basis of optimizing the suspension is the quarter suspension model of the test platform vehicle, which has been simplified and has certain limitations. In addition, only one optimization algorithm is used, which is not completely representative. In the future research process, the vehicle dynamics model will be continuously improved, and more optimization algorithms will be used to optimize the design of the suspension. For the special form of suspension, this article has certain guiding significance in the design of suspension, especially the low-chassis test platform vehicle similar to this article.

\section{Data Availability}

The data used to support the findings of this study are available from the corresponding author upon request.

\section{Conflicts of Interest}

The authors declare that there are no conflicts of interest regarding the publication of this paper.

\section{Acknowledgments}

This work was supported by the Key R\&D Projects in Hubei Province of China (Grant no. 2020BIB015). The authors are grateful for the support.

\section{References}

[1] V. K. Kukkala, J. Tunnell, S. Pasricha, and T. Bradley, “Advanced driver-assistance systems: a path toward autonomous vehicles," IEEE Consumer Electronics Magazine, vol. 7, no. 5, pp. 18-25, 2018.

[2] K. Massow and I. Radusch, "A rapid prototyping environment for cooperative advanced driver assistance systems," Journal of Advanced Transportation, vol. 2018, Article ID 2586520, 32 pages, 2018.

[3] J. Jia, B. Li, and X. Li, "Research on the radiated immunity test methods of ADAS functions in intelligent vehicles," $S A E$ Technical Paper 2018-01-1636, p. 6, 2018.

[4] J. Zhou, R. Schmied, A. Sandalek, H. Kokal, and L. del Re, "A framework for virtual testing of ADAS," SAE International Journal of Passenger Cars-Electronic and Electrical Systems, vol. 9, no. 1, pp. 66-73, 2016.

[5] J. Silberling, G. Nicols, W. Buller, and J. Lenkeit, "Development of a procedure to correlate, validate and confirm radar characteristics of surrogate targets for ADAS testing," $S A E$ Technical Paper 2020-01-0716, 2020, p. 7, 2020.

[6] EURO NCAP, Euro NCPA Test Protocol-AEB Systems, Version 1.0, 2019. 
[7] D. Zeitvogel, A. Ahlert, J. Neubeck et al., "An innovative test system for holistic vehicle dynamics testing," SAE Technical Paper 2019-01-0449, 2019.

[8] H. P. Schöner, W. Hurich, and D. Haaf, Selbstfahrendes Soft Crash Target zur Erprobung vonFahrerassistenzsystemen, Konferenz AAET, Iowa City, IA, USA, 2011.

[9] A. Aparicio, S. Baurès, J. Bargalló et al., "Pre-crash performance of collision mitigation and avoidance systems: results from the assess project," in Proceedings of the 34th FISITA World Automotive Congress, vol. 9, pp. 489-505, Beijing, China, November 2012.

[10] R. Schram, A. Williams, and M. Ratingen, "Implementation of autonomous emergency breaking (AEB), the next step in Euro NCAP's safety assessment," in Proceedings of the International Technical Conference on the Enhanced Safety of Vehicles 23rd, Seoul, South Korea, May 2013.

[11] J. Kelly, P. Broen, J. Silberling, N. Bozin, and J. Zellner, Devices, Systems, and Methods for Testing Crash Avoidance Technologies, Dynamic Resources, Inc., New York, NY, USA, 2012.

[12] N. C. A. P. Euro, Euro NCPA Global Vehicle Target Specification, 2018, https://cdn.euroncap.com/media/39159/tb-025global-vehicle-target-specification-for-euro-ncap-v10.pdf.

[13] J. Zhang, W. Li, G. Liu, Z. Zhang, and J. Chen, An Unmanned Testing Platform Vehicle, China Patent CN111380699A, 2020.

[14] C. Du, J. Shao, J. Xiong et al., Unmanned Driving Testing Platform Vehicle Transmission System, China Patent CN111005995A, 2020.

[15] M. Huang, W. Li, and L. Wang, A Platform Vehicle for ADAS Testing, China Patent CN110044642A, 2019.

[16] W. Li, W. Zhou, Z. Liu et al., Mobile Testing Platform Vehicle with Overload Protection Structure, China Patent CN209387301U, 2019.

[17] H. L. Simonetti, V. S. Almeida, F. A. Neves, and M. Greco, "Multi-objective topology optimization using the boundary element method," Structure, vol. 19, pp. 84-95, 2019.

[18] G. Papaioannou and D. Koulocheris, "An approach for minimizing the number of objective functions in the optimization of vehicle suspension systems," Journal of Sound and Vibration, vol. 435, pp. 149-169, 2018.

[19] S. Li, J. Xu, H. Gao, T. Tao, and X. Mei, "Safety probability based multi-objective optimization of energy-harvesting suspension system," Energy, vol. 209, 2020.

[20] D. Peng, G. Tan, K. Fang, L. Chen, P. K. Agyeman, and Y. Zhang, "Multi-objective optimization of an off-road vehicle suspension parameter through a genetic algorithm based on the particle swarm optimization," Mathematical Problems in Engineering, vol. 2021, Article ID 9640928, 14 pages, 2020.

[21] S. Kanarachos, A. M. Dizqah, G. Chrysakis, and M. E. Fitzpatrick, "Optimal design of a quadratic parameter varying vehicle suspension system using contrast-based fruit fly optimisation," Applied Soft Computing, vol. 62, pp. 463$477,2018$.

[22] Z. Xu, X. Huang, and F. Xu, "Parameters optimization of vibration isolation and mitigation system for precision platforms using non-dominated sorting genetic algorithm," Mechanical Systems and Signal Processing, vol. 128, pp. 191201, 2019.

[23] B. Gadhvi, V. Savsani, and V. Patel, "Multi-objective optimization of vehicle passive suspension system using NSGA-II, SPEA2 and PESA-II," Procedia Technology, vol. 23, pp. 361368, 2016.

[24] G. G. Fossati, L. F. F. Miguel, and W. J. P. Casas, "Multiobjective optimization of the suspension system parameters of a full vehicle model," Optimization and Engineering, vol. 20, no. 1, pp. 151-177, 2019.

[25] D. Özcan, Ü. Sönmez, and L. Güvenç, "Optimisation of the nonlinear suspension characteristics of a light commercial vehicle," International Journal of Vehicular Technology, vol. 2013, Article ID 562424, 16 pages, 2013.

[26] G. Papaioannou and D. Koulocheris, "Multi-objective optimization of semi-active suspensions using KEMOGA algorithm," Engineering Science and Technology, an International Journal, vol. 22, no. 4, pp. 1035-1046, 2019.

[27] K. Chen, S. He, E. Xu, R. Tang, and Y. Wang, "Research on ride comfort analysis and hierarchical optimization of heavy vehicles with coupled nonlinear dynamics of suspension," Measurement, vol. 165, Article ID 108142, 2020.

[28] L. Zhang, J. Liu, F. Pan, S. Wang, and X. Ge, "Multi-objective optimization study of vehicle suspension based on minimum time handling and stability," Proceedings of the Institution of Mechanical Engineers-Part D: Journal of Automobile Engineering, vol. 234, no. 9, pp. 2355-2363, 2020.

[29] H. Pang, Y. Chen, J. Chen, and X. Liu, "Design of LQG controller for active suspension without considering road input signals," Shock and Vibration, vol. 2017, Article ID 6573567, 13 pages, 2017.

[30] G. I. Y. Mustafa, H. P. Wang, and T. Yang, "Vibration control of an active vehicle suspension systems using optimized model-free fuzzy logic controller based on time delay estimation," Advances in Engineering Software, vol. 127, pp. 141-149, 2019.

[31] J. Zou, X. Guo, M. A. A. Abdelkareem, L. Xu, and J. Zhang, "Modelling and ride analysis of a hydraulic interconnected suspension based on the hydraulic energy regenerative shock absorbers," Mechanical Systems and Signal Processing, vol. 127, pp. 345-369, 2019.

[32] X. Meng, J. Chang, X. Wang, and Y. Wang, "Multi-objective hydropower station operation using an improved cuckoo search algorithm," Energy, vol. 168, pp. 425-439, 2019.

[33] Y. Yusoff, M. S. Ngadiman, and A. M. Zain, "Overview of NSGA-II for optimizing machining process parameters," Procedia Engineering, vol. 15, pp. 3978-3983, 2011. 